\title{
Intracoronary and Retrograde Coronary Venous Myocardial Delivery of Adipose-Derived Stem Cells in Swine Infarction Lead to Transient Myocardial Trapping with Predominant Pulmonary Redistribution
}

\author{
Soon Jun Hong, MD, $\mathrm{PhD}^{1,2,3,6}$, Dongming Hou, MD, $\mathrm{PhD}^{1,2,3}$, Todd J. Brinton, $\mathbf{M D}^{5}$, Brian \\ Johnstone, PhD $^{1,2,3}$, Dongni Feng, BS ${ }^{3}$, Pamela Rogers, LATG ${ }^{1,2,3}$, William F. Fearon, MD $^{5}$, \\ Paul Yock, MD ${ }^{5}$, and Keith L. March, MD, PhD ${ }^{1,2,3,4}$ \\ ${ }^{1}$ Krannert Institute of Cardiology, Indianapolis, IN, USA \\ ${ }^{2}$ Indiana Center for Vascular Biology and Medicine, Indianapolis, IN, USA \\ ${ }^{3}$ Indiana University School of Medicine, Indianapolis, IN, USA \\ ${ }^{4}$ R.L. Roudebush Veterans Affairs Medical Center, Indianapolis, IN, USA \\ ${ }^{5}$ Stanford University School of Medicine, Stanford, CA, USA \\ ${ }^{6}$ Korea University Anam Hospital, Seoul, Korea
}

\begin{abstract}
Objectives-To examine the comparative fate of adipose-derived stem cells (ASCs) as well as their impact on coronary microcirculation following either retrograde coronary venous or arterial delivery.
\end{abstract}

\begin{abstract}
Background-Local delivery of ASCs to the heart has been proposed as a practical approach to limiting the extent of myocardial infarction. Mouse models of mesenchymal stem cell effects on the heart have also demonstrated significant benefits from systemic (intravenous) delivery, prompting a question about the advantage of local delivery. There has been no study addressing the extent of myocardial vs. systemic disposition of ASCs in large animal models following local delivery to the myocardium.
\end{abstract}

Methods-In an initial experiment, dose-dependent effects of ASC delivery on coronary circulation in normal swine were evaluated to establish a tolerable ASC dosing range for intracoronary delivery. In a set of subsequent experiments, an anterior acute myocardial infarction (AMI) was created by balloon occlusion of the proximal left anterior descending (LAD) artery, followed by either intracoronary (IC) or retrograde coronary venous (RCV) infusion of $10^{7111}$ Indium-labeled autologous ASCs 6 days following AMI. Indices of microcirculatory resistance (IMR) and coronary flow reserve (CFR) were measured before sacrifices to collect tissues for analysis at 1 or 24 hours after cell delivery.

Address Correspondence to: Keith L. March MD, PhD, $1481 \mathrm{~W} 10^{\text {th }}$ St., C3109, Veterans Affairs Medical Center, Indianapolis, IN 46202, Tel: (317) 988-4976, kmarch@iupui.edu. 
Results-IC delivery of porcine ASCs to normal myocardium was well-tolerated up to a cumulative dose of $14 \times 10^{6}$ cells (approximately $0.5 \times 10^{6}$ cells $/ \mathrm{kg}$ ). There was evidence suggesting microcirculatory trapping of ASC: at unit doses of $50 \times 10^{6}$ ASCs, IMR and CFR were found to be persistently altered in the target LAD distribution at 7 days following delivery, while at $10 \times 10^{6}$ ASCs, only CFR was altered. In the context of recent MI, a significantly higher percentage of ASCs was retained at 1 hour with IC delivery compared to RCV delivery $(57.2 \pm 12.7 \%$ vs. $17.9 \pm$ $1.6 \%, \mathrm{p}=0.037)$ but this initial difference was not apparent at 24 hours $(22.6 \pm 5.5 \%$ vs. $18.7 \pm$ $8.6 \% ; \mathrm{p}=0.722$ ). In both approaches, most ASC redistributed to the pulmonary circulation by 24 hours post-delivery. There were no significant differences in CFR or IMR following ASC delivery to infarcted tissue by either route.

Conclusions-Selective intravascular delivery of ASC by coronary arterial and venous routes leads to similarly limited myocardial cell retention with predominant redistribution of cells to the lungs. Intracoronary arterial delivery of ASC leads to only transiently greater myocardial retention, which is accompanied by obstruction of normal regions of coronary microcirculation at higher doses. The predominant intrapulmonary localization of cells following local delivery via both methods prompts the notion that systemic delivery of ASC might provide similarly beneficial outcomes while avoiding risks of inadvertent microcirculatory compromise.

\section{Keywords}

adipose-derived stem cells; swine model; acute myocardial infarction; microcirculatory resistance; intracoronary delivery; retrograde coronary venous delivery

\section{INTRODUCTION}

Adipose-derived stem cells (ASCs) can be readily obtained in large numbers by minimally invasive techniques for autologous use to promote repair and rescue of cardiac tissues following myocardial injury. The potential therapeutic effects of ASC in promoting reduced scarring and increased revascularization have been demonstrated in animal models of myocardial infarction (MI), heart failure, and hindlimb ischemia (1). These clear benefits as well as the potential for autologous use have led to early clinical trials in patients (2-3). The beneficial outcomes in cardiovascular disease models appear to occur predominantly through paracrine effects (4-6) as well as acceleration of neovascularization (7-8), rather than via direct regeneration through differentiation of ASCs.

Various clinically feasible modalities for local cell delivery to treat acute MI (AMI) patients include intracoronary (IC), retrograde coronary venous (RCV), endocardial injection, and open-chest epicardial injection(9-12). It was recently shown that IC delivery of ASCs is more effective than transendocardial delivery in increasing neovascularization(13). The efficiency of stem cell retention following vascular delivery to the heart presumably depends on sufficient cellular extravasation into surrounding myocardial tissues, as well as local growth factor gradients and surface receptor interactions. However, the degree to which this initial cellular localization is truly necessary for efficacy is not well understood in light of the growing recognition of the role of distant paracrine actions in mediating stem cell effects. To comparatively assess the efficiency as well as potential adverse consequences of cell delivery, we conducted a series of studies in both normal and infarcted swine heart, 
evaluating the short-term fate and dose-dependent effects on microcirculation of ASCs delivered into the vascular system by either a venous route (retrograde coronary venous), which potentially averts microvessel sludging by cells which do not migrate out of the vessel, or the more commonly employed arterial route (intracoronary).

\section{METHODS}

\section{Overall Study Designs}

Animal handling and care followed the recommendations of the National Institute of Health guide for the care and use of laboratory animals. All protocols were approved by the animal care and use committee at Indiana University School of Medicine. A series of three experimental protocols was conducted: 1) a dose-escalation study for intracoronary delivery involved three pigs; 2 ) a study of the effects of two doses of intracoronary ASC (or saline control) on coronary vasculature in normal myocardium utilized twelve pigs; and 3) a study of ASC biodistribution comparing IC and RCV local delivery methods involved fourteen pigs. All pigs were Yorkshire domestic $(25-35 \mathrm{~kg})$ of mixed gender.

In the third protocol, animals received myocardial infarction by proximal left anterior descending (LAD) artery occlusion as described below. Six days after ischemia, these animals were randomly assigned to 2 groups: IC group $(n=7)$ and RCV group $(n=7)$. Every animal in these treatment groups received $10^{7111}$ Indium (In)-labeled autologous ASCs six days following MI. Animals were then evaluated for cell distribution by $\gamma$ counting of tissue samples and whole-body imaging 1 hour ( $\mathrm{n}=8,4$ animals from each group) and 24 hours ( $\mathrm{n}=6,3$ animals from each group) after cell delivery. ASCs would be able to survive and provide more benefits to damaged microvascular structure when given between 3 to 7 days after MI(14-15).

\section{Intracoronary Dose Escalation Study}

Allogeneic porcine ASC was used for IC dose-escalation study, and 3 animals received a series of increasing doses of ASC without making MI. An initial $300 \mathrm{U} / \mathrm{kg}$ heparin bolus was administered with additional $100 \mathrm{U} / \mathrm{kg}$ heparin provided hourly. First for dose escalation study in 3 swine, an angioplasty balloon was inflated at low pressure in the proximal LAD artery just distal to the first septal perforator after coronary angiogram. A 10 $\mathrm{ml}$ volume of cells was infused over 45 seconds. Angioplasty balloon was deflated after 3 minutes. The dose was escalated at $1,3,10,30,100 \times 10^{6}$ with 30 minutes interval. A coronary angiogram as well as left ventriculogram was obtained at 15 minutes following each infusion. Images were acquired in order to measure LV wall motion and beats to fill up distal LAD with contrast, and images were analyzed by using Phillips 2.01 LV analysis software. LV ejection fraction (LVEF) was calculated using the centerline method. Mean arterial pressure (MAP) and LV end-diastolic pressure (LVEDP) were measured before and after each dose.

\section{CFR and IMR Measurements of Left Anterior Descending Artery}

After the gradual dose escalation study, 12 additional swine were randomized into 3 groups: control group ( $\mathrm{n}=4,5 \%$ serum with $0.9 \%$ normal saline injection), low-dose group $(\mathrm{n}=4,10$ 
$\times 10^{6}$ ASC injection), and high-dose group ( $\mathrm{n}=4,50 \times 10^{6} \mathrm{ASC}$ injection). To evaluate for the occurrence and persistence of altered microcirculatory function after cell delivery, IMR and CFR were measured using a pressure wire technique, in each pig at baseline, 1-hour post delivery, and 7-day post delivery. After LAD engagement and coronary angiography, a 0.014 inch fiberoptic pressure-temperature sensor-tipped guidewire (Radi Medical Systems, Uppsala, Sweden) was equalized to the guiding catheter pressure with the sensor positioned at the ostium of the guiding catheter and positioned as distal as possible in the LAD. Proximal aortic and distal intracoronary pressures were recorded simultaneously. Papaverine $5 \mathrm{mg}$ was used as the hyperemic agent. The mean transit time at rest and during hyperemia were recorded after rapid injection of $3 \mathrm{ml}$ of room-temperature saline through the guiding catheter. The hyperemic and resting mean transit times were repeated 3 times, and the mean value was used for the analysis. Thermodilution-derived CFR was calculated as the resting mean transit time divided by the hyperemic mean transit time(16). The IMR was defined as simultaneously measured distal coronary pressure multiplied by the thermodilution-derived hyperemic mean transit time [mm Hg seconds or units (U)]. The mean transit time at rest and during hyperemia was measured with commercially available software (Radi Medical Systems). After calibration of the pressure sensor at the guiding catheter tip, the wire was placed into the distal $1 / 3$ of the $\mathrm{LAD}$, followed by infusion of $3 \mathrm{ml}$ saline at room temperature and measurement of transit time by thermodilution. This was repeated 3 times, followed by injection of $5 \mathrm{mg}$ papaverine to induce hyperemia, and an additional sequence of 3 saline injections with thermodilution measurements conducted after confirming a distal LAD pressure drop of $>10 \mathrm{mmHg}$.

\section{Delivery Methods}

Intracoronary Delivery-Six days after MI, coronary angiography was repeated to assess the LAD. An angioplasty balloon of equivalent size to the proximal LAD was inflated at low pressure (2 atm) at the site of previous balloon inflation, and $10^{7111}$ In-labeled cells $(10 \mathrm{ml})$ were delivered at a rate of $1.3 \mathrm{ml} / \mathrm{min}$ with alternating 3 minute infusions and 3 minute periods of reperfusion upon deflation of the angioplasty balloon.

Retrograde Coronary Venous Delivery-Venous access was obtained via the internal jugular vein. The coronary venous system was then cannulated using a novel, investigational double-balloon catheter (Venomatrix, Inc. CA). This device is made of 2 catheters: a proximal outer catheter with a large balloon $(1.0 \times 0.5 \mathrm{~cm})$, and a distal inner catheter with a smaller balloon $(0.5 \times 0.5 \mathrm{~cm})$. The distal balloon was applied to minimize washout of delivered cells into the systemic circulation via distal, low-resistance venovenous anastomoses. First, the coronary sinus was engaged using the proximal catheter that has a pre-curved tip for simple cannulation. Then the proximal catheter was advanced into the proximal interventricular vein (AIV) using a 0.014-inch flexible guidewire. A coronary sinus venogram was performed initially to delineate anatomy and provide a roadmap for subsequent cannulations. Afterward, the distal catheter was pushed through the proximal device and advanced into the mid-to-distal AIV. Catheter placement was confirmed angiographically by injection of $1-2 \mathrm{~mL}$ of diluted non-ionic contrast agent into the AIV, and proper positioning was confirmed by the presence of significant contrast blush in the area of the myocardium between the 2 balloons. To achieve better delivery in a pre-defined 
myocardial area, the distance between the proximal and distal balloons was kept around 2.5 $\mathrm{cm}$. Subsequently, $10^{7111}$-In labeled cells in $10 \mathrm{~mL}$ saline with $5 \%$ autologous porcine serum were infused between the 2 balloons at $300 \mathrm{~mm} \mathrm{Hg}$ over 15 seconds, and the 2 balloons were deflated after 5 minutes to achieve maximum local delivery. Continuous hemodynamic monitoring was maintained during the whole procedure using a femoral arterial sheath.

\section{Tissue Harvesting and Measurement of Radioactivity}

Animals were euthanized 1 hour and 24 hours after cell delivery by a lethal dose of pentobarbital $(65 \mathrm{mg} / \mathrm{kg})$. The hearts were removed and placed on ice for processing. Each heart was transversely sliced into 5 sections of 1.5 - to $2.0-\mathrm{cm}$ thickness along the apicalbasal axis before further subdividing into 8 wedge shaped pieces of approximately equal dimensions. The distribution of the injected radioactive cells was assessed by qualitative whole-body radioactive scans (Ecat Exact HR+PET scanner, 63 planes, 15.5-cm field of view) with a resolution of $4.2 \mathrm{~mm}$, and $\gamma$-counter (Packard Auto-Gamma Cobra II) was used for further quantification of radioactivity of harvested tissue samples. Technetium-99 LV perfusion images were coupled with ${ }^{111}$ In-labeled ASC images for direct visualization by dual isotope SPECT images. Harvested tissue samples from various organs (lungs, heart, liver, spleen, and kidneys, and musculoskeleton) and delivery system were measured and corrected for whole organ weight where appropriate. Approximately $1 \mathrm{~g}$ piece of tissue from each organ was collected for measurements of radioactive counts. $\gamma$-count values of tissues harvested 1 hour and 24 hours after each delivery were multiplied in each case by the total weight of the respective organ, and $\gamma$-count percentages of each visceral organ was defined as the ratio of the locally retained radioactivity to the total radioactivity placed in the delivery device. $\gamma$-count percentages of 5 major organs (heart, lung, liver, kidney, and spleen) were calculated by the ratio of the locally retained radioactivity to the sum of total radioactivity of 5 major organs.

\section{Statistics}

Results are presented as mean \pm SD. Data were compared using a Mann-Whitney $U$ test and 1-way ANOVA test (GraphPad InStat software, San Diego, CA), with differences between data sets considered significant if $\mathrm{P}<0.05$.

Animal Catheterization, Isolation and Labeling of Porcine Autologous ASC, and Myocardial Infarction Model are found in the Detailed Supplemental Methods

\section{RESULTS}

\section{Study Animals with Myocardial Infarction}

Ventricular arrhythmias occurred during each coronary balloon occlusion. Cardioversion was successful in all animals, but 5 animals died suddenly 30 minutes to 8 hours following MI due to intractable VF. The volume of infarcted LV myocardium, which was derived by multiplying the thickness of each section by the areas of infarction, was $22 \pm 5 \%$ in the IC group and $20 \pm 4 \%$ in the RCV group (P=NS). 
LVEF decreased from above $60 \%$ to less than $40 \%$ following MI in both groups, with no differences between groups (Fig. 1B). Heart rate 6 days after MI demonstrated no differences between groups ( $105 \pm 8 \mathrm{bpm}$ in the IC group and $109 \pm 8 \mathrm{bpm}$ in the RCV group, $\mathrm{p}=0.703)$. Systolic $(110 \pm 7 \mathrm{mmHg}$ in the IC group and $103 \pm 8 \mathrm{mmHg}$ in the RCV group, $\mathrm{p}=0.329)$ and diastolic blood pressure $(72 \pm 6 \mathrm{mmHg}$ in the IC group and $70 \pm$ $7 \mathrm{mmHg}$ in the RCV group, $\mathrm{p}=0.659)$ showed no differences between groups. Fractional shortening 6 days after MI showed no differences between groups $(24.3 \pm 4.1 \%$ in the IC group and $23.8 \pm 3.8 \%$ in the RCV group, $\mathrm{p}=0.769$ ). $\mathrm{LV}$-end diastolic diameter (LVEDD) ( $3.32 \pm 0.41 \mathrm{~cm}$ in the IC group and $3.38 \pm 0.37 \mathrm{~cm}$ in the RCV group, $\mathrm{p}=0.512)$ and LV-end systolic diameter (LVESD) $(2.51 \pm 0.35 \mathrm{~cm}$ in the IC group and $2.57 \pm 0.32 \mathrm{~cm}$ in the RCV group, $\mathrm{p}=0.487) 6$ days after MI showed no differences between groups. Decreases in MAP from baseline to day 6 were $62 \pm 8 \mathrm{mmHg}$ to $43 \pm 6 \mathrm{mmHg}$ in the IC group and from $61 \pm 7$ $\mathrm{mmHg}$ to $45 \pm 5 \mathrm{mmHg}$ in the RCV group. Serum troponin levels were similar 24 hours after MI in both groups $(1.27 \pm 0.30 \mathrm{ng} / \mathrm{mL}$ in the IC group and $1.17 \pm 0.36 \mathrm{ng} / \mathrm{mL}$ in the $\mathrm{RCV}$ group, $\mathrm{p}=0.578)$.

\section{Evaluation of Heart Function in Relation to Dose}

Blood flow to the distal LAD, measured under fluoroscopy by counting the number of heart beats required to fill this region of the vessel with contrast, was not changed at bolus doses up to $10 \times 10^{6} \mathrm{ASCs}$ (cumulative dose of $14 \times 10^{6} \mathrm{ASCs}$ ); however, further doses in the escalation series of $30 \times 10^{6} \mathrm{ASC}$ (cumulative dose $44 \times 10^{6} \mathrm{ASCs}$ ) and then $100 \times 10^{6}$ ASC injections (cumulative dose $144 \times 10^{6} \mathrm{ASCs}$ ) resulted in a sharp decrease in filling time (Fig. 2). No significant changes in LV wall motion were revealed until administration of the $100 \times 10^{6}$ dose, which caused hypokinesia at apical anterior wall. This dose also caused a slight decrease in LVEF (results not shown), and induced VF.

Based on these observations, a subsequent analysis was performed comparing single bolus IC administration of ASCs in three groups of swine. Doses administered were $10 \times 10^{6}$ ASCs (low dose), $50 \times 10^{6}$ ASCs (high dose) or vehicle control. Microvascular function and LV contractility were analyzed with IMR, CFR, and by left ventriculogram. A significant increase from baseline in IMR was noted 7 days after ASC delivery in the high-dose group $(11.0 \pm 1.3$ vs. $17.8 \pm 3.2, \mathrm{p}=0.04$, respectively) (Fig. 3A). Significant decreases from baseline in CFR were noted in both the low-dose and high-dose groups at 7 days after delivery (Fig. 3B). There were no instances of VF and no significant changes in LVEDP or LVEF (Fig. 3C) were noted in all 3 groups.

\section{Distribution of ASC after IC and RCV Delivery following Myocardial Infarction}

Representative planar $\gamma$-scan images demonstrate that ${ }^{111}$ In-labeled ASCs were present in the LV wall 1 hour after either IC or RCV delivery to infarcted hearts (Fig. 4A). The delivery system such as syringe and catheter was thoroughly evaluated for remaining radioactivity after ASC delivery. An average of $13 \pm 3 \%$ of labeled ASC was noted to remain in the delivery system immediately following injection, and $45 \pm 10 \%$ of delivered ASCs were distributed among the 5 major organs: lung, heart, liver, kidneys and spleen. The remaining $42 \pm 12 \%$ was in the musculoskeletal system and circulating blood. 
Quantitative analysis of the delivery distribution expressed as a percentage of delivery to the major thoracoabdominal organs at 1 hour after delivery demonstrated significantly higher $(\mathrm{p}=0.037)$ initial myocardial retention with IC $(57.2 \pm 12.7 \%)$ than with RCV $(17.9 \pm 1.6 \%)$ delivery (Fig. 4B). A greater portion of retained cells was detected in the lungs at one hour after RCV delivery $(75.3 \pm 4.7 \%)$ compared to IC delivery $(23.4 \pm 12.4 \%)$. However, there was no difference in percentage of retained cells in the myocardium at 24 hours after IC $(22.6 \pm 5.5 \%)$ or RCV $(18.7 \pm 8.6 \%)$ delivery (Fig. 4C). An equivalent proportion of ASCs was also detected in the lungs at 24 hours after either IC and RCV delivery $(59.7 \pm 4.1 \%$ and $71.7 \pm 10.2 \%$ ) (Fig. 4C).

A comprehensive sectioning of the hearts was performed to determine the cell distribution within the myocardium with respect to infarct location. ASCs delivered by the IC method distributed mainly to the LV anterolateral segment $(25.6 \pm 4.9 \%)$, apical segments (26.2 \pm $6.1 \%)$, and anterior right ventricle $(19.5 \pm 5.3 \%)$. In contrast, ASCs delivered by the RCV method distributed mainly to the atria $(18.1 \pm 5.7 \%)$, right ventricle $(20.2 \pm 6.3 \%)$, and inferolateral segment of LV $(29.8 \pm 6.8 \%)$.

The relative tolerability of both delivery methods with respect to microcirculation post-MI was equivalent. Both IMR (Fig. 5A) and CFR measurements (Fig. 5B) were similar between the 2 groups at baseline, pre-ASC delivery ( 6 days after MI), and post-ASC delivery ( 1 hour after cell delivery).

\section{DISCUSSION}

ASCs represent one of the most practical therapeutic cell candidates to augment vascular growth and tissue repair, since ASCs can be readily isolated and harvested in large quantities with a minimally invasive liposuction for autologous use. A number of mechanisms of action may contribute to the therapeutic effects of ASCs, including secretion of angiogenic and anti-apoptotic factors (4,7,17-19), transdifferentiation into cardiomyocytes (20-21) or vascular cells $(8,22-23)$, and promotion of endogenous repair by resident progenitor cells both locally and at a distance(1). Critical paracrine effects of ASCs in the repair of ischemic tissues have also been demonstrated in multiple studies (24-26). These effects may occur at a distance, possibly even when ASCs become trapped in the lung (27). In complementary studies, the key contribution of paracrine factors secreted by ASC was demonstrated by knockdown of HGF synthesis which led to markedly reduced ability of ASC to promote angiogenesis in ischemic muscle tissue(19), and systemic neutralization of SDF-1 activity, which led to decreased blood flow recovery in ischemic tissue following ASC administration.(17)

Although several studies regarding IC delivery of ASCs after MI have been conducted in animals $(13,28-30)$ and more recently in humans(2), there has been no consensus regarding the optimal delivery method with regard to efficacy and safety. In this study, we initially evaluated normal animals in order to sensitively identify effects of IC ASC delivery on the coronary microcirculation. We observed that IC delivery of less than $14 \times 10^{6}$ ASCs did not obstruct coronary artery flow in the target vessel of swine, while a dramatic increase in the number of beats required to fill the distal LAD was observed after IC delivery of cumulative 
doses exceeding $44 \times 10^{6}$ ASCs, suggesting significant microvascular occlusion. To further evaluate these effects, we compared microvascular integrity among a control group (vehicle only), a low-dose group (10 $\left.\times 10^{6} \mathrm{ASCs}\right)$, and a high-dose group $\left(50 \times 10^{6} \mathrm{ASCs}\right)$. An increase in IMR at 7 days was observed after delivery of the high dose of cells, but not with the lower dose.

Rigol et al (13) suggested that injecting cells into the coronary circulation was more effective in neovascularization than direct myocardial cell injections, partially due to a paracrine effect. Since IC or RCV deliveries both provide direct intravascular access and do not require separate intramyocardial instrumentation, we elected to comparatively study these techniques for the first time with regard to acute distribution of ${ }^{111}$-In labeled ASCs to visceral organs. While myocardial ASC retention in swine MI model was higher 1 hour after IC delivery than RCV delivery, this difference was not apparent by 24 hours after delivery. Distribution in major non-target organs at 24 hours was also similar for ASCs delivered by either IC or RCV. Cells delivered at the optimal dose by either method had no remaining impact on microvascular integrity after 7 days. Therefore, both IC and RCV methods appear to be safe and similarly effective. This study may suggest that the comparative suitability of each delivery modality may be related to the ischemic area. Delivery by IC resulted in ASCs localizing mainly to the LV anterolateral segment, apical segments, and anterior right ventricle; whereas RCV resulted in localization of ASCs to the atria, right ventricle, and inferolateral segment of LV. It is possible that IC delivery could be more beneficial to patients with anteroapical MI and RCV delivery method in patients with inferolateral ischemia or MI. Recent delivery of bone marrow mononuclear cells using the RCV approach has shown the tolerability of this approach in patients with refractory angina(10).

For many years, it has been widely presumed that enhancing localization of cells to direct delivery to a target tissue would play an important role in promoting the beneficial effects of the cells. This has been so because of the hypotheses that key cellular effects involve transdifferentiation, fusion, or other mechanisms that require cellular proximity. Our study reveals that only a limited fraction of ASC are retained locally following two approaches to intravascular delivery to the myocardial microcirculation, much as we demonstrated previously with peripheral blood mononuclear cells(14). Furthermore, inadvertent intracoronary delivery of ASCs to normal myocardium is accompanied by induction of microcirculatory abnormalities. Taken together with the progressive understanding that a major mechanism of ASC therapeutic effects involve paracrine secretions by ASCs, and recent findings that ASCs embolized within the lung following systemic venous infusion are active in secreting therapeutic molecules(27,31), we speculate that intravenous delivery of ASC may indeed confer benefits of cardiac protection while eliminating the potential for disruptions in the coronary microcirculation

IC Delivery of cultured swine ASC is well-tolerated even in non-infarcted myocardium, up to a cumulative dose of 14 million cells (approximately 0.5 million cells $/ \mathrm{kg}$ ). However, we would suggest that higher doses be administered with particular caution to selectively deliver ASC only to ischemically-threatened myocardium, in order to limit the possibility of microvascular compromise and possible additional injury to border-zone tissue. Although the organ distribution of ASC was similar 24 hours after either IC or RCV delivery method, 
the localization of ASCs within the heart differed. If these findings in the porcine heart extend to humans, our findings may support selection of delivery techniques based on desired distribution of cells.

There are a few limitations in this study. Since we observed the safety of IC delivery of ASC up to 7 days, a long-term follow-up is warranted to verify the safety of delivered ASC.

Moreover, the persistence and distribution of ASCs after 24 hours must be investigated, as well as the long-term safety and efficacy of either IC or RCV delivery. Finally, the results of this study may only pertain to ASC and may not extrapolate to other types of MSC or stem/ progenitor cells derived from other tissues.

\section{Conclusions}

The observation of predominant redistribution of ASC to the pulmonary circulation within 24 hours following delivery to infarcted myocardium highlights the need for further understanding about the relative beneficial contribution of localized vs. distant cells in the context of infarction limitation. While many studies have focused on mechanisms operative at a local level, these reports cannot exclude the possibility that many of the cellular contributions to therapy are indeed-mediated by cells distant from the myocardium. Our study provides a clear rationale for the exploration of the functional consequences of intravenous delivery of ASC in models of AMI and ultimately in the clinical setting.

\section{Supplementary Material}

Refer to Web version on PubMed Central for supplementary material.

\section{Acknowledgments}

We thank Michele Schlegelmilch for editorial assistance. This work was supported by National Institutes of Health grants R01 HL077688 (KLM), VA Merit Review Award (KLM), the Cryptic Mason's Medical Research Foundation, and the IUPUI Signature Center for Vascular and Cardiac Adult Stem Cell Therapy.

\section{References}

1. Hong SJ, Traktuev DO, March KL. Therapeutic potential of adipose-derived stem cells in vascular growth and tissue repair. Curr Opin Organ Transplant. 2010; 15(1):86-91. [PubMed: 19949335]

2. Houtgraaf JH, den Dekker WK, van Dalen BM, Springeling T, de Jong R, van Geuns RJ, Geleijnse ML, Fernandez-Aviles F, Zijlsta F, Serruys PW, et al. First experience in humans using adipose tissue-derived regenerative cells in the treatment of patients with ST-segment elevation myocardial infarction. J Am Coll Cardiol. 2012; 59(5):539-40. [PubMed: 22281257]

3. Perin EC, Sanchez PL, Ruiz RS, Perez-Cano R, Lasso J, Alonso-Farto JC, Fernandez-Pina L, Serruys PW, Duckers HJ, Kastrup J, et al. Abstract 17966: First In Man Transendocardial Injection of Autologous AdiPose-deRived StEm Cells in Patients with Non RevaScularizable IschEmic Myocardium (PRECISE). Circulation. 2010; 122:A17966. 21_MeetingAbstracts.

4. Rehman J, Traktuev D, Li J, Merfeld-Clauss S, Temm-Grove CJ, Bovenkerk JE, Pell CL, Johnstone $\mathrm{BH}$, Considine RV, March KL. Secretion of angiogenic and antiapoptotic factors by human adipose stromal cells. Circulation. 2004; 109(10):1292-8. [PubMed: 14993122]

5. Wei X, Zhao L, Zhong J, Gu H, Feng D, Johnstone BH, March KL, Farlow MR, Du Y. Adipose stromal cells-secreted neuroprotective media against neuronal apoptosis. Neurosci Lett. 2009; 462(1):76-9. [PubMed: 19549558] 
6. Perin EC, Silva GV. Autologous cell-based therapy for ischemic heart disease: clinical evidence, proposed mechanisms of action, and current limitations. Catheter Cardiovasc Interv. 2009; 73(3): 281-8. [PubMed: 19213080]

7. Traktuev DO, Merfeld-Clauss S, Li J, Kolonin M, Arap W, Pasqualini R, Johnstone BH, March KL. A population of multipotent CD34-positive adipose stromal cells share pericyte and mesenchymal surface markers, reside in a periendothelial location, and stabilize endothelial networks. Circ Res. 2008; 102(1):77-85. [PubMed: 17967785]

8. Traktuev DO, Prater DN, Merfeld-Clauss S, Sanjeevaiah AR, Saadatzadeh MR, Murphy M, Johnstone BH, Ingram DA, March KL. Robust functional vascular network formation in vivo by cooperation of adipose progenitor and endothelial cells. Circ Res. 2009; 104(12):1410-20. [PubMed: 19443841]

9. Llano R, Epstein S, Zhou R, Zhang H, Hamamdzic D, Keane MG, Freyman T, Wilensky RL. Intracoronary delivery of mesenchymal stem cells at high flow rates after myocardial infarction improves distal coronaryblood flow and decreases mortality in pigs. Catheter Cardiovasc Interv. 2009; 73(2):251-7. [PubMed: 19085935]

10. Tuma J, Fernandez-Vina R, Carrasco A, Castillo J, Cruz C, Carrillo A, Ercilla J, Yarleque C, Cunza J, Henry TD, et al. Safety and feasibility of percutaneous retrograde coronary sinus delivery of autologous bone marrow mononuclear cell transplantation in patients with chronic refractory angina. J Transl Med. 2011; 9:183. [PubMed: 22029669]

11. Kim YS, Ahn Y. A long road for stem cells to cure sick hearts: update on recent clinical trials. Korean Circ J. 2012; 42(2):71-9. [PubMed: 22396692]

12. Sharif F, Bartunek J, Vanderheyden M. Adult stem cells in the treatment of acute myocardial infarction. Catheter Cardiovasc Interv. 2011; 77(1):72-83. [PubMed: 20506335]

13. Rigol M, Solanes N, Farre J, Roura S, Roque M, Berruezo A, Bellera N, Novensa L, Tamborero D, Prat-Vidal C, et al. Effects of adipose tissue-derived stem cell therapy after myocardial infarction: impact of the route of administration. J Card Fail. 2010; 16(4):357-66. [PubMed: 20350704]

14. Hou D, Youssef EA, Brinton TJ, Zhang P, Rogers P, Price ET, Yeung AC, Johnstone BH, Yock PG, March KL. Radiolabeled cell distribution after intramyocardial, intracoronary, and interstitial retrograde coronary venous delivery: implications for current clinical trials. Circulation. 2005; 112(9 Suppl):I150-6. [PubMed: 16159808]

15. Schachinger V, Erbs S, Elsasser A, Haberbosch W, Hambrecht R, Holschermann H, Yu J, Corti R, Mathey DG, Hamm CW, et al. Intracoronary bone marrow-derived progenitor cells in acute myocardial infarction. N Engl J Med. 2006; 355(12):1210-21. [PubMed: 16990384]

16. Pijls NH, De Bruyne B, Smith L, Aarnoudse W, Barbato E, Bartunek J, Bech GJ, Van De Vosse F. Coronary thermodilution to assess flow reserve: validation in humans. Circulation. 2002; 105(21): 2482-6. [PubMed: 12034653]

17. Kondo K, Shintani S, Shibata R, Murakami H, Murakami R, Imaizumi M, Kitagawa Y, Murohara T. Implantation of adipose-derived regenerative cells enhances ischemia-induced angiogenesis. Arterioscler Thromb Vasc Biol. 2009; 29(1):61-6. [PubMed: 18974384]

18. Kim Y, Kim H, Cho H, Bae Y, Suh K, Jung J. Direct comparison of human mesenchymal stem cells derived from adipose tissues and bone marrow in mediating neovascularization in response to vascular ischemia. Cell Physiol Biochem. 2007; 20(6):867-76. [PubMed: 17982269]

19. Cai L, Johnstone BH, Cook TG, Liang Z, Traktuev D, Cornetta K, Ingram DA, Rosen ED, March KL. Suppression of hepatocyte growth factor production impairs the ability of adipose-derived stem cells to promote ischemic tissue revascularization. Stem Cells. 2007; 25(12):3234-43. [PubMed: 17901400]

20. Leobon B, Roncalli J, Joffre C, Mazo M, Boisson M, Barreau C, Calise D, Arnaud E, Andre M, Puceat M, et al. Adipose-derived cardiomyogenic cells: in vitro expansion and functional improvement in a mouse model of myocardial infarction. Cardiovasc Res. 2009; 83(4):757-67. [PubMed: 19505931]

21. Planat-Benard V, Menard C, Andre M, Puceat M, Perez A, Garcia-Verdugo JM, Penicaud L, Casteilla L. Spontaneous cardiomyocyte differentiation from adipose tissue stroma cells. Circ Res. 2004; 94(2):223-9. [PubMed: 14656930] 
22. Planat-Benard V, Silvestre JS, Cousin B, Andre M, Nibbelink M, Tamarat R, Clergue M, Manneville C, Saillan-Barreau C, Duriez M, et al. Plasticity of human adipose lineage cells toward endothelial cells: physiological and therapeutic perspectives. Circulation. 2004; 109(5):656-63. [PubMed: 14734516]

23. Miranville A, Heeschen C, Sengenes C, Curat CA, Busse R, Bouloumie A. Improvement of postnatal neovascularization by human adipose tissue-derived stem cells. Circulation. 2004; 110(3):349-55. [PubMed: 15238461]

24. Takahashi M, Suzuki E, Oba S, Nishimatsu H, Kimura K, Nagano T, Nagai R, Hirata Y. Adipose tissue-derived stem cells inhibit neointimal formation in a paracrine fashion in rat femoral artery. Am J Physiol Heart Circ Physiol. 2010; 298(2):H415-23. [PubMed: 19940081]

25. Rajashekhar G, Traktuev DO, Roell WC, Johnstone BH, Merfeld-Clauss S, Van Natta B, Rosen ED, March KL, Clauss M. IFATS collection: Adipose stromal cell differentiation is reduced by endothelial cell contact and paracrine communication: role of canonical Wnt signaling. Stem Cells. 2008; 26(10):2674-81. [PubMed: 18669909]

26. Wang L, Deng J, Tian W, Xiang B, Yang T, Li G, Wang J, Gruwel M, Kashour T, Rendell J, et al. Adipose-derived stem cells are an effective cell candidate for treatment of heart failure: an MR imaging study of rat hearts. Am J Physiol Heart Circ Physiol. 2009; 297(3):H1020-31. [PubMed: 19574490]

27. Lee RH, Pulin AA, Seo MJ, Kota DJ, Ylostalo J, Larson BL, Semprun-Prieto L, Delafontaine P, Prockop DJ. Intravenous hMSCs improve myocardial infarction in mice because cells embolized in lung are activated to secrete the anti-inflammatory protein TSG-6. Cell Stem Cell. 2009; 5(1): 54-63. [PubMed: 19570514]

28. Byun KH, Kim SW. Is stem cell-based therapy going on or out for cardiac disease? Korean Circ J. 2009; 39(3):87-92. [PubMed: 19949592]

29. Valina C, Pinkernell K, Song YH, Bai X, Sadat S, Campeau RJ, Le Jemtel TH, Alt E. Intracoronary administration of autologous adipose tissue-derived stem cells improves left ventricular function, perfusion, and remodelling after acute myocardial infarction. Eur Heart J. 2007; 28(21):2667-77. [PubMed: 17933755]

30. Fotuhi P, Song YH, Alt E. Electrophysiological consequence of adipose-derived stem cell transplantation in infarcted porcine myocardium. Europace. 2007; 9(12):1218-21. [PubMed: 17951268]

31. Danchuk S, Ylostalo JH, Hossain F, Sorge R, Ramsey A, Bonvillain RW, Lasky JA, Bunnell BA, Welsh DA, Prockop DJ, et al. Human multipotent stromal cells attenuate lipopolysaccharideinduced acute lung injury in mice via secretion of tumor necrosis factor-alpha-induced protein 6 . Stem Cell Res Ther. 2011; 2(3):27. [PubMed: 21569482] 


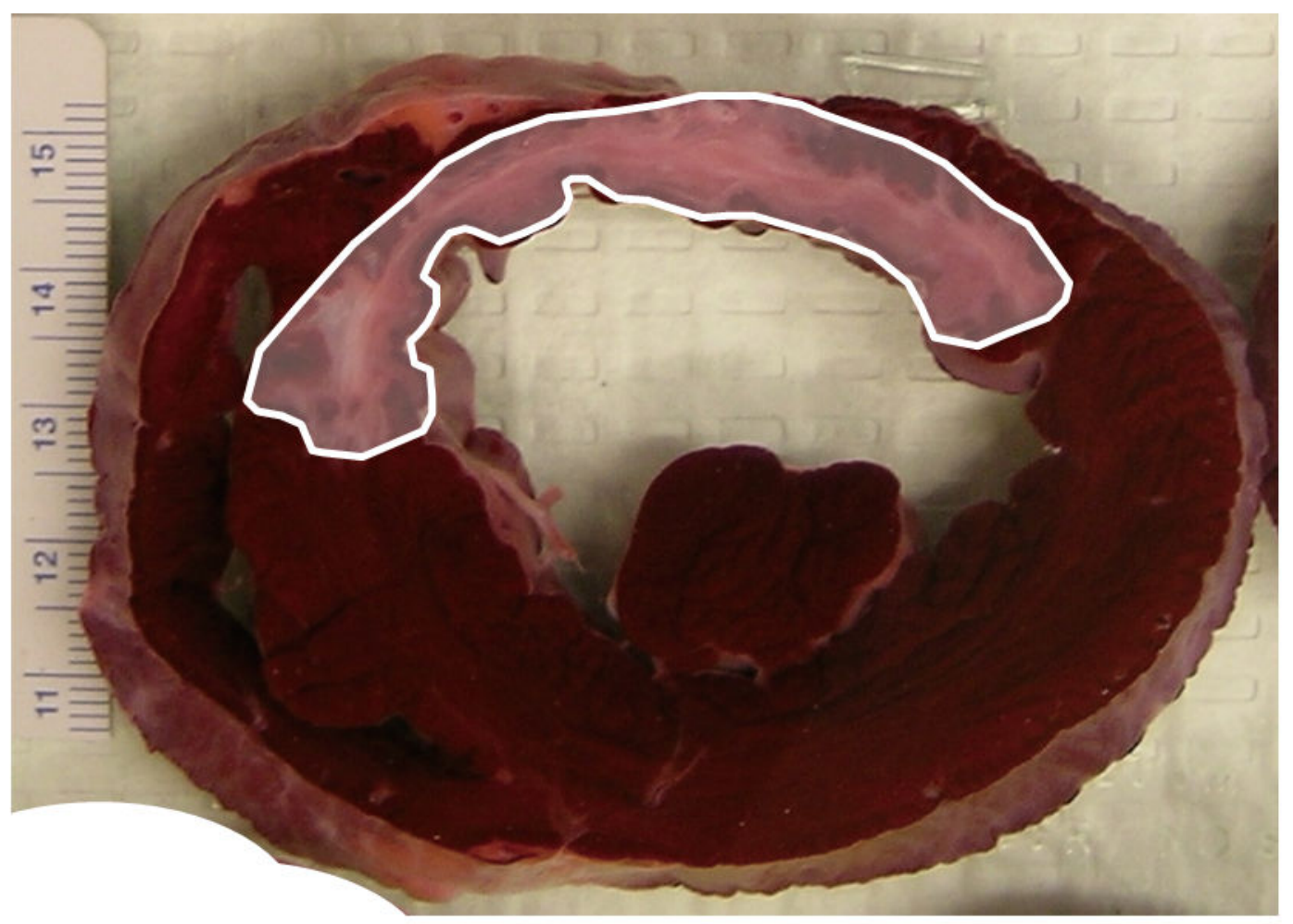




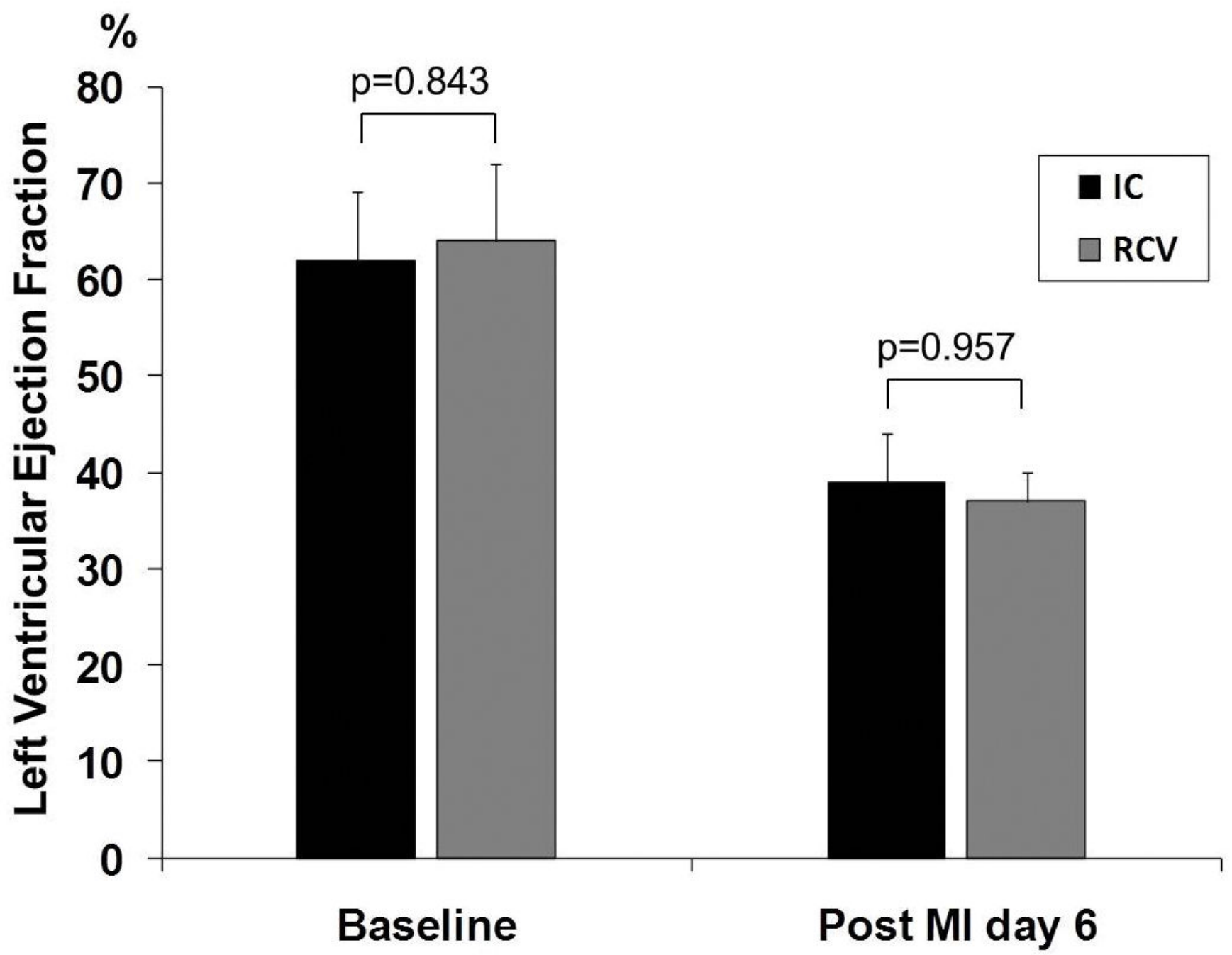

Fig. 1.

Study animal with myocardial infarction. A) Extensive anteroseptal myocardial infarction was created by occluding proximal left anterior descending artery for 45 minutes.

Myocardial infarction created by the coronary occlusion and reperfusion injury is delineated with TTC staining in pale area outlined by solid white line. B) The left ventricular ejection fraction (LVEF) was calculated before and 6 days after left anterior descending artery occlusion. Average values were measured from 7 animals in each group. LVEF showed no significant differences between the 2 groups before and after myocardial infarction. 


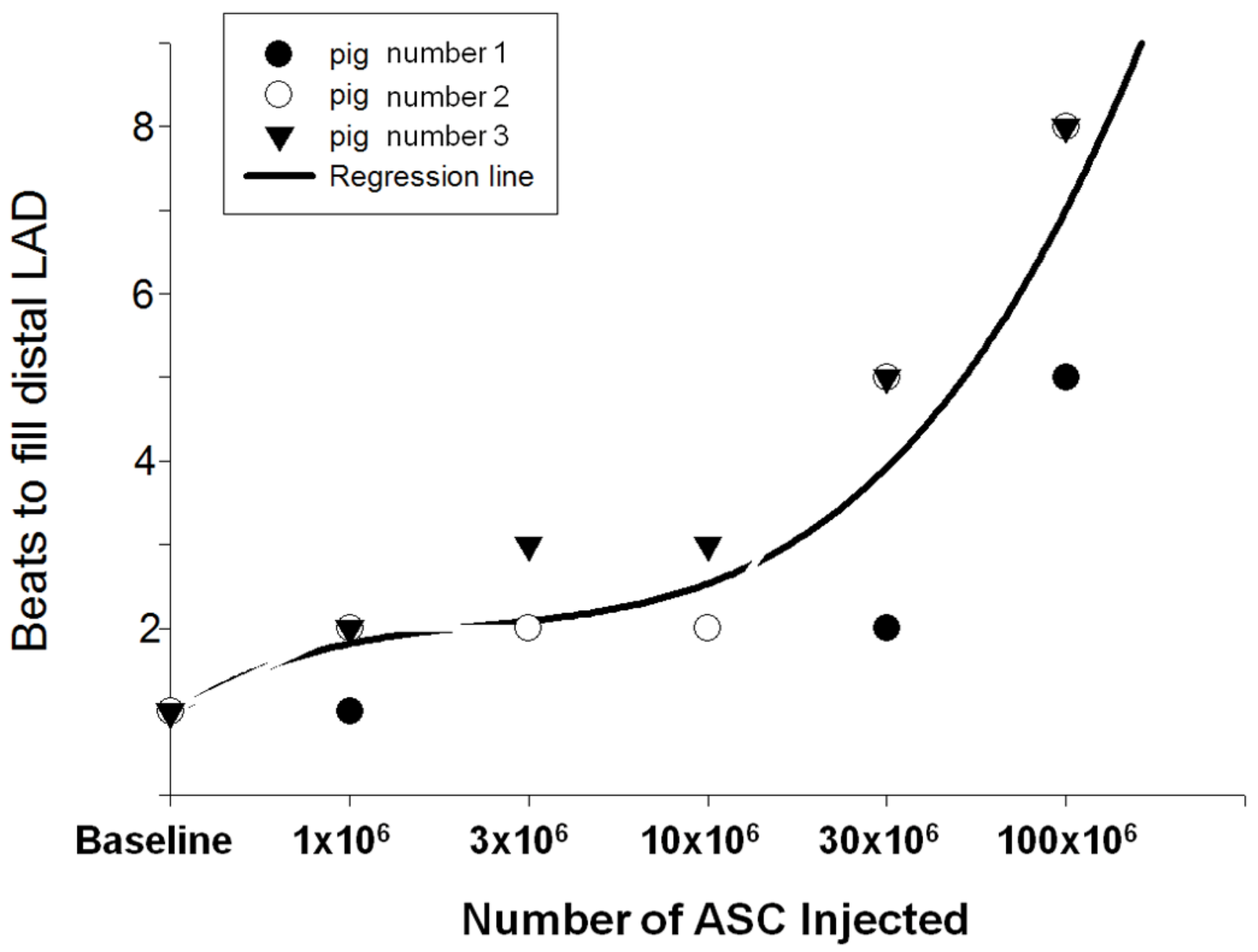

Fig. 2.

Normal myocardium model. As the cumulative number of adipose-derived stem cell (ASC) injection was increased, the beats to fill distal left anterior descending artery (LAD) increased at the same time. A large increase in the beats to fill distal LAD was seen between $30 \times 10^{6}$ ASC (a cumulative dose of $44 \times 10^{6}$ ASC) and $100 \times 10^{6}$ ASC (a cumulative dose of $144 \times 10^{6}$ ASC) injections. 

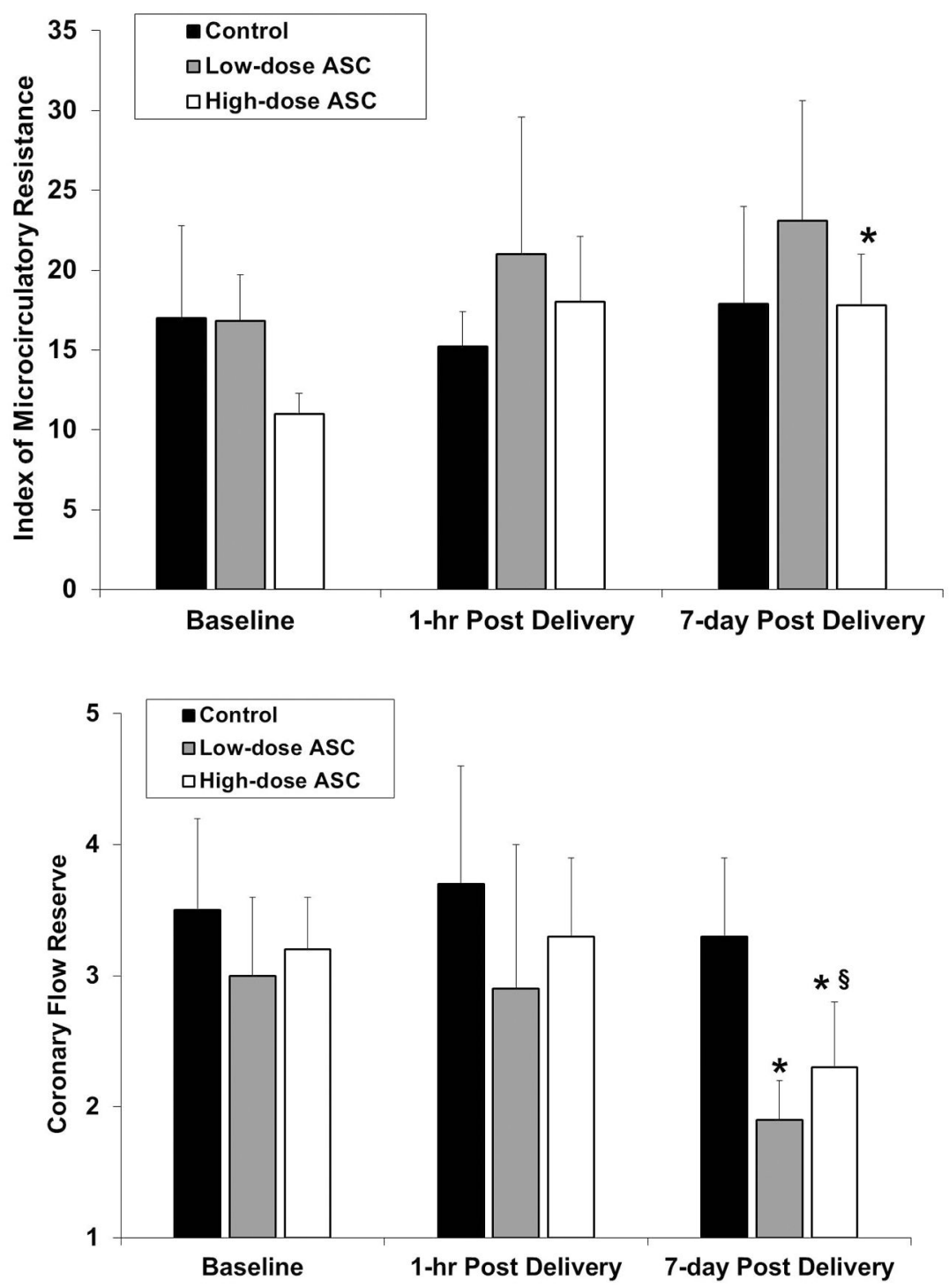


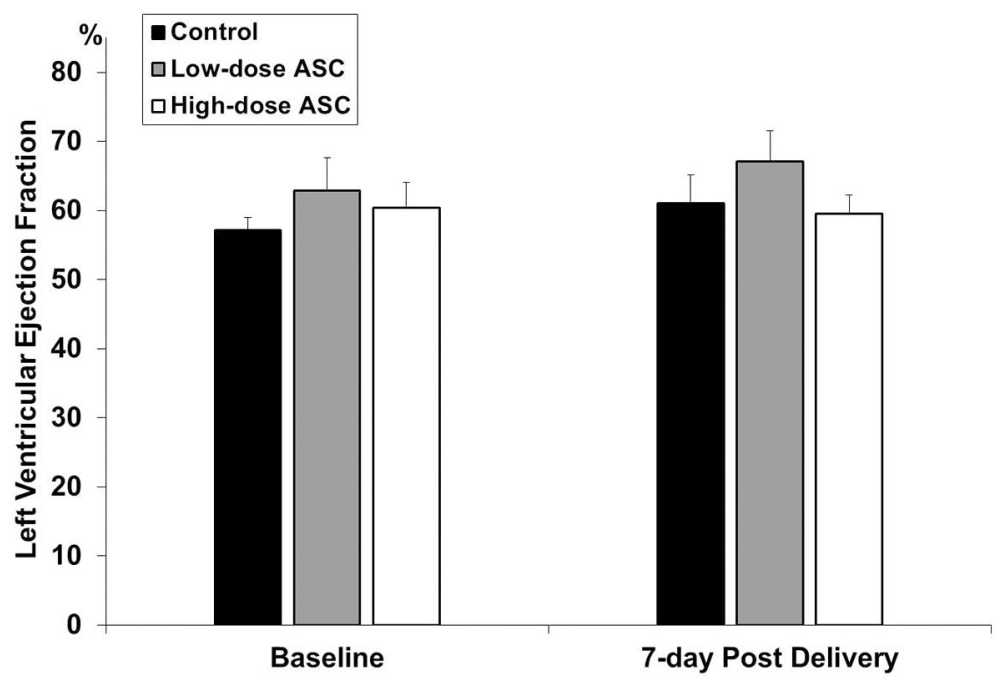

Fig. 3.

Normal myocardium model. A) A significant increase from baseline in the index of microcirculatory resistance (IMR) was noted only in the high-dose group 7 days after adipose-derived stem cell (ASC) delivery ( $* \mathrm{p}<0.05$ vs. baseline). B) Significant decreases from baseline in coronary flow reserve (CFR) were noted in the low-dose and high-dose groups 7 days after ASC delivery (* $\mathrm{p}<0.05$ vs. baseline), and the 7-day CFR was significantly lower than 1-hour CFR only in the high-dose group ( $\$ \mathrm{p}<0.05$ vs. 1-hr post delivery). C) No significant left ventricular ejection fraction changes were noted before and after ASC delivery in all 3 groups. 


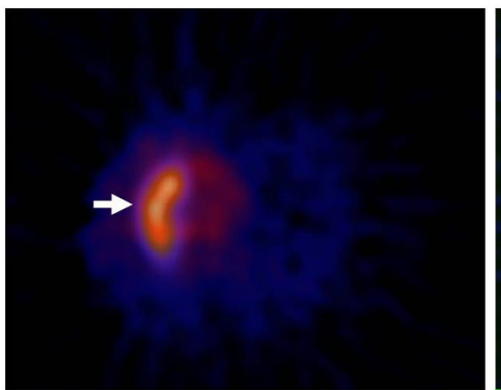

Intracoronary

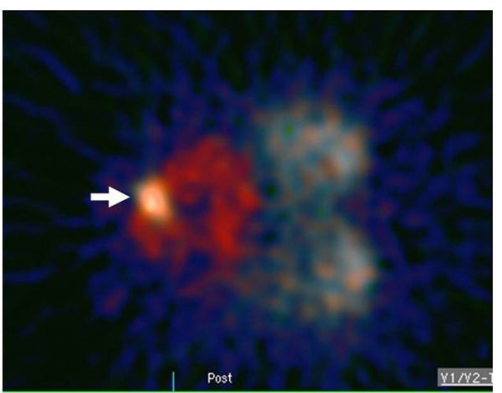

Retrograde Coronary Venous
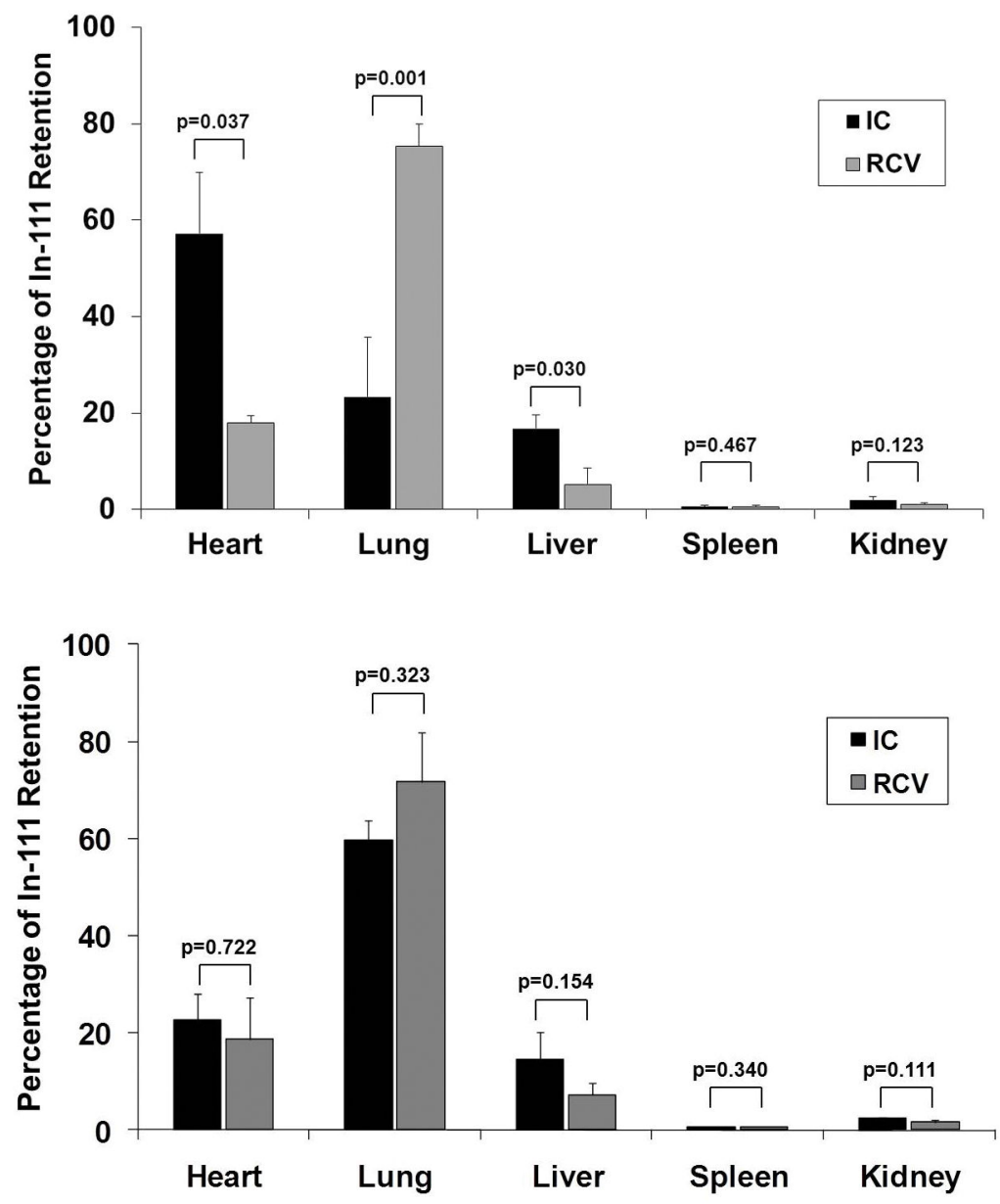

Fig. 4.

Post-myocardial infarction model. A) Direct visualization by dual isotope SPECT images 1 hour after either intracoronary (IC) or retrograde coronary venous (RCV) delivery into porcine heart. Distribution of ${ }^{111}$ In-labeled adipose-derived stem cells (ASCs) (white arrows) is shown in left ventricular short axis view coupled with ${ }^{99} \mathrm{Tc}$ left ventricular perfusion images (red doughnut shaped ring). B) Significantly higher myocardial ASC retention $(57.2 \pm 12.7 \%$ vs. $17.9 \pm 1.6 \%, \mathrm{p}=0.037$, respectively) with significantly lower lung ASC retention was noted 1 hour after IC delivery when compared to RCV delivery. C) Myocardial ASC retention was similar between the 2 groups 24 hours after IC and RCV 
deliveries ( $22.6 \pm 5.5 \%$ vs. $18.7 \pm 8.6 \%, \mathrm{p}=0.722$, respectively) with the majority of ASCs in the lung $(59.7 \pm 4.1 \%$ vs. $71.7 \pm 10.2 \%, \mathrm{p}=0.323$, respectively $)$. 

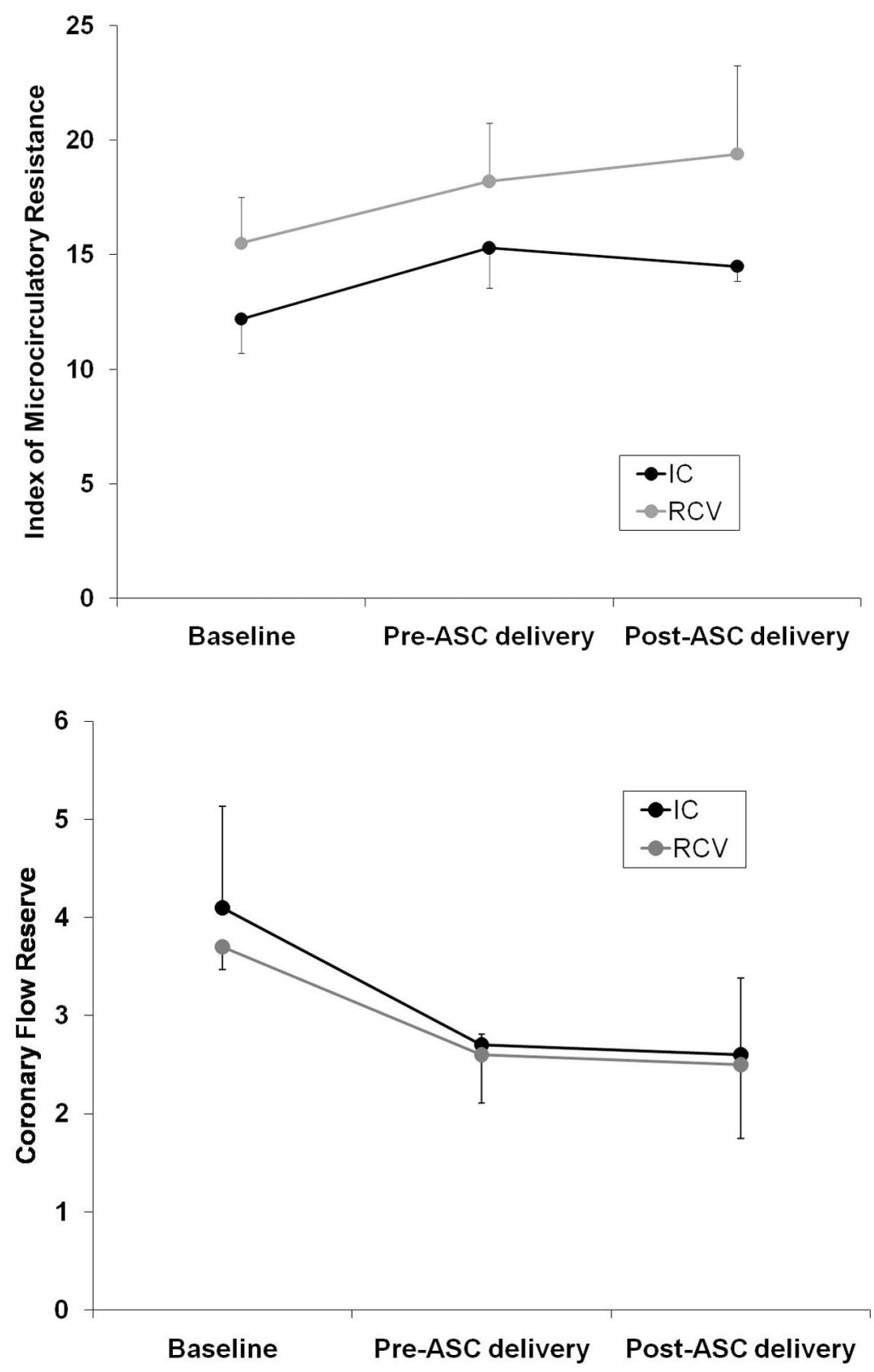

Fig. 5.

Post-myocardial infarction model. IMR (Fig. 5A) and CFR measurements (Fig. 5B) were similar between the 2 groups at baseline, pre-ASC delivery (6 days after MI), and post-ASC delivery (1 hour after cell delivery). 